Ecology, 81(6), 2000, pp. 1758-1759

(C) 2000 by the Ecological Society of America

\title{
Theoretical Ecology Meets Agroecology: Towards an Ecological Approach to Agroecosystems
}

Hawkins, Bradford A., and Howard Vernon Cornell, editors. 1999. Theoretical approaches to biological control. Cambridge University Press, New York, xii +412 p. $\$ 105.00$, ISBN: 0-521-57283-5.

The modern agroecosystem emerged as a hybrid of production traditions extending back many generations and production technologies born of the nineteenth century. Its maturity came only after World War II, when chemicals developed in war research found a ready market on farms trying to deal with age-old problems of soil fertility and pest control. The resulting system, which we today call conventional, is a model of productivity, causing marginal farmlands to be productive and enabling good farmlands to be even more productive. But, as is now acknowledged by most observers, this cornucopian production has come with a cost—contamination of wells and waterways, potentially carcinogenic residues in food, non-sustainable use of the resources on which the system depends, loss of biodiversity, and so forth. Indeed, much of the basis of the environmental movement stimulated by Rachael Carson's Silent spring had to do with problems generated by the conventional agroecosystem.

Developing in parallel with the conventional system was an alternative-actually a collection of alternatives, but referred to here simply as the alternative for convenience. Rather than rely on a simplistic notion of Liebig's law of the minimum to indicate which readily soluble ions to introduce into the soil, the alternative emphasized wise stewardship of soil organic matter as much for good plant nutrition as for good soil physical structure. Rather than rely on a specific chemical poison to kill a pest, the alternative emphasized management practices that would minimize emergence of pests in the first place. This alternative agriculture in many ways looks like the agriculture done before the industrial revolution, but in other ways goes beyond. Today it stands as a minor component, filling a so-called "niche" market, in the multibillion dollar agriculture business that still dominates much of world trade.

Adherents of the alternative model, have long promoted the idea that agroecosystem development should be based on sound ecological principles and have suggested that much of what is wrong with the conventional system stems from ignorance of those principles, either purposefully or through naiveté. Ecological principles indeed are unavoidably involved in agricultural development. Consequently the science of ecology ought to be the science behind the engineering of ecosystems to become agroecosystems. Currently it is not. It is obvious to all concerned that the agroecosystem is an ecosystem in all the traditional senses of that word, and that it thus must conform to the rules of ecosystems as much as any other. Yet the study of agroecosystems from this point of view remains marginal in both the discipline of ecology and the various disciplines normally emphasized in conventional agriculture research. This is unfortunate for the future of the planet. If ecology is to become to agriculture what physics is to mechanical engineering (as many in the alternative movement propose), ecologists must pursue the application of their science to agricultural problems and must allow agricultural problems to be part of the determinant of where the science should to be moving.

In this context, "Theoretical approaches to biological control" by Brad Hawkins and Howard Cornell is more than just another book about ecological theory or the ecology of a particular management problem. It is a magnificent example of just the sort of synthesis that is needed to promote the alternative system and, more importantly, stands as an example for the way in which this synthesis can come about. In 21 chapters, this book shows how fundamental principles of theoretical ecology can be brought to bear on this real problem for the alternative movement and, perhaps more importantly, illustrates how focusing on a real world problem can motivate the development of interesting ecological theory.

The chapters are grouped into five main themes ("Biological control theory: past and present"; "Ecological considerations"; "Spatial considerations"; "Genetic/evolutionary considerations"; "Microbes and pathogens") and the editors provide excellent brief summaries of all chapters at the beginning of each of the five sections. While the first section 
is largely historical review, the rest of the chapters are reports on original work, summaries of particular themes, or presentations of work on very particular systems. Each and every chapters contains something of interest to both ecologist and biological control practitioner.

Especially interesting are three review-like chapters, "Recent developments in theory for biological control of insect pests by parasitoids" by Briggs, Murdoch, and Nisbet, "Models in biological control: a field guide" by Barlow, and "The dynamics of insect-pathogen interactions" by Godfray and Briggs. Barlow and colleagues summarize six distinct structured models of insect/parasitoid interactions with major insights for biological control. It is an excellent example of how general ecological theory can provide important qualitative insights to a practical problem. Briggs summarizes 50 published models of biological control from the past 20 years, and does an admirable job of finding generalization from a remarkable diversity of modeling approaches. Godfray and Briggs actually break significant new ground, since the question of pathogens in biological control is relatively new for theoretical ecology. Beginning with the Anderson/May model of infectious diseases, they elaborate not only on the theory itself but on the underlying biology and how theory needs to be modified to account for the particular exigencies of biological control.

The range of subjects covered is large. From the use of native natural enemy generalists to the consequences of three trophic level dynamics, from outbreaks to stability theory, from spatial considerations to evolutionary considerations, the collection embraces an impressive array of subject mater. Yet I doubt anyone will charge that superficiality accompanies the decision to cast a broad net. For the most part each chapter could stand on its own as a solid contribution to a professional peer-reviewed journal.
The book does not shy away from some of the more complicated problems involved in theoretical applications to ecological problems. Some of the well-known eccentricities recently emerging from non-linear dynamics (such as chaotic trajectories, multiple attractors, and the structure of basins of attraction) are dealt with explicitly. The temptation to reach for the large supposedly holistic systems models so popular in the 1960s is largely resisted by most of the authors, and is even a danger explicitly cited by several of them. Barlow, for example, elegantly summarizes the issue as "[models in bio control] are offering concrete predictions at a useful level, and ... have outgrown the initial temptation offered by computer simulation technology, to develop unnecessary and confusing complexity. This is one of the every-present dangers for specific models, just as that for strategic models is to forget that the goal is to understand, not the behavior of models, but the behavior of nature.'

For such a large collection one normally expects a great deal of variability in quality. However the editors somehow managed to squeeze out the best of each contributor. Each and every chapter is well written, well referenced and timely. Indeed the book is a model of how theoretical work should be focused on practical problems. If ecology is to be the scientific basis of the new agriculture, this book may turn out to be the first applied engineering text. I only hope others will take it as inspiration to deal with the myriad of other problems facing the movement for a new, more sustainable agroecology.

\section{JOHN VANDERMEER}

University of Michigan

Department of Biology

Ann Arbor, Michigan 48109 